\title{
Assessment of Tannin Variation in Tamarisk Foliage Across a Latitudinal Gradient
}

\author{
Amanda M. Hussey ${ }^{\mathrm{a}, 1}$, Bruce A. Kimball ${ }^{\mathrm{b}, *}$ and Jonathan M. Friedman ${ }^{\mathrm{c}}$ \\ ${ }^{a}$ Monell Chemical Senses Center, 3500 Market Street, Philadelphia, PA, 19104, USA \\ ${ }^{b}$ United States Department of Agriculture, Animal and Plant Health Inspection Service, Wildlife Services, \\ National Wildlife Research Center, Monell Chemical Senses Center, 3500 Market Street, Philadelphia, PA, 19104, USA \\ ${ }^{c}$ U.S. Geological Survey, Fort Collins Science Center, 2150 Centre Avenue, Building C, Fort Collins, CO 80526 \\ ${ }^{I}$ Present Address: University of Massachusetts Amherst, Department of Chemistry, 710 North Pleasant St, Amherst, MA, \\ 01003, USA
}

\begin{abstract}
Certain phenotypic traits of plants vary with latitude of origin. To understand if tannin concentration varies among populations of tamarisk (Tamarix spp.) according to a latitudinal gradient, an analytical method was adapted from an enological tannin assay. The tannin content (wet basis) of tamarisk foliage collected from 160 plants grown in a common garden ranged from 8.26 to $62.36 \mathrm{mg} / \mathrm{g}$ and was not correlated with the latitude of the original North American plant collection site. Tannins do not contribute to observed differences in herbivory observed among these tamarisk populations.
\end{abstract}

Keywords: Tannin, invasive plant, Tamarix spp., ultraviolet spectroscopy.

\section{INTRODUCTION}

Tannins, both hydrolysable and condensed, and monoterpenes represent the two most common types of the so-called "quantitative" plant defense compounds [1]. These antifeedant compounds are produced in relatively large concentrations and are considered to be energetically costly to produce [2]. Tannins reduce the nutritional quality of forage by binding soluble proteins in the gut [3]. Some mammals are capable of counteracting this effect by deploying proline-rich salivary proteins to bind tannins and render them inactive [3]. Occurrence of these proteins is specific only in cases when a certain type of tannin is consumed (obligate herbivores), and more generalized in the case of indiscriminate tannin consumers (generalist herbivores). However, the lack of such proteins does not always preclude utilization of tannin-rich foods in herbivore diets. For instance, beavers (Castor canadensis) are able to bind and digest linear condensed tannins via specific salivary proteins, but do not possess salivary proteins that bind quebracho tannin [3]. Yet, beavers were shown to consume artificial diets containing quebracho tannin as well as tamarisk (Tamarix spp.), a tannin-containing plant not normally considered part of the beaver diet [4].

Tamarisk, or salt cedar, was introduced to North America from Eurasia in the 1800's for ornamental and erosion

*Address correspondence to this author at the United States Department of Agriculture, Animal and Plant Health Inspection Service, Wildlife Services, National Wildlife Research Center, Monell Chemical Senses Center, 3500 Market Street, Philadelphia, PA, USA, 19104; Fax: +1 215898 2084; Voice: +1 267519 4930; E-mail: bruce.a.kimball@aphis.usda.gov prevention purposes [5]. Tamarisk is considered high in polyphenolic compounds, and low in most nutritional compounds [6]. Tamarisk has invaded extensively and is now the second most abundant riparian plant in the western United States [7]. Tamarisk is an adequate nutritional source for some insects. Moline and Poff examined crane fly (Tipula sinotipula) growth when fed a diet consisting of tamarisk leaf litter and concluded that tamarisk is a viable food source as the larvae grew rapidly on the tamarisk diet [8]. Similarly, caddis flies (Lepidostoma unicolor) grew significantly when fed a diet of tamarisk leaf litter, indicating that tamarisk may be a feasible short term nutritional source [6].

In the present study, we adapted a methyl cellulose precipitation method (see [9] and [10] ) to quantify tannins in tamarisk foliage collected from a common garden experiment representing multiple North American latitudes. Other traits, such as cold hardiness, have been found to vary with latitude of origin [11]. Thus, we evaluated tannin concentrations across this same gradient.

\section{MATERIALS AND METHODS}

\section{Reagents}

All chemicals were ACS certified or HPLC grade. Aqueous solutions were prepared with HPLC grade water (Fisher Scientific, Fair Lawn, NJ, USA). Ascorbic acid, dimethylformamide (DMF), ethanol, and dimethyl sulfoxide (DMSO) were also purchased from Fisher Scientific. Tannic acid (A.C.S. reagent), ethanol, ammonium sulfate, and methyl cellulose-1500 cP were purchased from Sigma Aldrich (St. Louis, MO, USA). 


\section{Materials and Equipment}

Disposable, low-UV cuvettes were employed for spectroscopic analysis (Plastibrand; Fisher Scientific) with a Thermo Scientific Genesys 6 spectrophotometer (Madison, WI, USA). Samples were ground using a KitchenAid ${ }^{\mathbb{R}}$ coffee grinder (St. Joseph, MI, USA). Extracts were agitated with a Fisher Scientific Multitube Vortexer and solutions were filtered through $25 \mathrm{~mm}$ syringe filters, PTFE $0.45 \mu \mathrm{m}$ (Fisher Scientific). A FoodSaver ${ }^{\circledR}$ vacuum sealer system and gallonsize freezer bags (Jarden Consumer Solutions, Boca Raton, FL, USA) were used for plant sample storage.

\section{Solutions}

A $0.04 \%$ methyl cellulose solution was prepared weekly. The solution was stored at $4^{\circ} \mathrm{C}$ and remade as needed. Methyl cellulose solution was best when used 3-11 days following preparation. The extraction solvent (1:1 DMF:1 $\mathrm{mM}$ ascorbic acid) was prepared every other day and stored at $4^{\circ} \mathrm{C}$. A saturated ammonium sulfate solution was prepared as needed.

\section{Plant Material}

Tamarisk foliage was collected from a common garden planted in a clay-loam field on 16 August 2005 in Fort Collins, Colorado from rooted cuttings [11]. Tamarisks in the garden were Tamarix ramosissima Ledeb., T. chinensis Lour., and hybrids of the two. This garden included tamarisk plants collected along a latitudinal gradient from southern Texas to northern Montana (32.0 to $\left.47.6^{\circ} \mathrm{N}\right)$. Microsatellite markers showed gradual latitudinal genetic variation. Collections from southern locations were more similar to $T$. chinensis while collections from northern locations were more similar to $T$. ramosissima [11]. Sample foliage (leaf and stem) was collected on 12 June 2007 from 161 genetically distinct individuals. Samples were placed in freezer bags, immediately vacuum-sealed and maintained frozen until homogenized. A subset of the samples $(n=60)$ were submitted to a commercial lab for forage analyses by standard wet methods. Moisture data indicated that water content (\%) varied little among the samples (mean $=74.1 \%$; RSD $=$ $3.5 \%)$.

Foliage was processed by adding dry ice to the stainless steel coffee grinder and grinding to a uniform consistency (similar to snow). Green foliage was added to the dry ice mixture and ground for approximately 45 seconds until the dry ice and foliage mixture became a course powder. The mixture was stored in an unsealed vacuum bag at $-6^{\circ} \mathrm{C}$ until the carbon dioxide was removed by sublimation. The bags were vacuum sealed and the sample remained frozen until subjected to the analysis.

\section{Extraction of Plant Samples}

Approximately two grams of ground plant material (wet) were placed in a $25 \mathrm{ml}$ culture tube and the mass was accurately determined. Exactly $15.0 \mathrm{ml}$ of extraction solvent was added and the tube was placed on the vortex mixer for one hour, allowed to sit for one hour, and mixed for an additional hour. The extract was decanted into a second culture tube and the sample was extracted a second time with $10.0 \mathrm{ml}$ of the extraction solvent by mixing for one hour on the vortex mixer. The extracts were combined and the final volume was assumed to be $25.0 \mathrm{ml}$.

\section{Tannin Precipitation Treatments}

Adapting the method of Sarneckis et al. [10], plant extracts were diluted in $50 \%$ ethanol $(500 \mu$ of extract to $10 \mathrm{ml}$ of $50 \%$ ethanol) and two $750 \mu \mathrm{l}$ aliquots of the dilution were transferred to separate $10-\mathrm{ml}$ culture tubes containing $500 \mu \mathrm{l}$ of saturated $\left(\mathrm{NH}_{4}\right)_{2} \mathrm{SO}_{4}$. One $\mathrm{ml}$ of $0.04 \%$ methyl cellulose was added to one tube and $1.0 \mathrm{ml}$ of water (control) was added to the other. Samples were then mixed thoroughly by vortex and allowed to stand for 30 minutes. For UV/Vis determination, methyl cellulose precipitate solutions were filtered using syringe PTFE filters (controls were not filtered).

\section{Ultraviolet Spectroscopy}

Working standards were prepared for each analysis from a $10 \mathrm{mg} / \mathrm{mL}$ tannic acid concentrated standard solution at three concentrations $(\sim .001,0.12,0.25 \mathrm{mg} / \mathrm{ml})$ in $1: 1$ ethanol:water. Standard solutions were subjected to the precipitation procedures as described previously for sample extracts to produce methyl cellulose and control treatments.

Absorbance at $280 \mathrm{~nm}$ was determined for working standard solutions and prepared extracts by placing approximately $1.5 \mathrm{ml}$ of the appropriate solution in a 1-cm disposable cuvette. The precipitation absorbance $\left(\mathrm{Abs}_{\mathrm{ppt}}\right)$ was determined from the absorbance of the methyl cellulose treatment $\left(\mathrm{Abs}_{\text {cell }}\right)$ and the control treatment $\left(\mathrm{Abs}_{\text {raw }}\right)$ according to the equation: $\left(\mathrm{Abs}_{\mathrm{ppt}}\right)=\left(\mathrm{Abs}_{\mathrm{raw}}\right)-\left(\mathrm{Abs}_{\mathrm{cell}}\right)$.

Unique calibration curves $\left(\mathrm{Abs}_{\mathrm{ppt}}\right.$ versus tannin concentration) were produced from working standards for each analysis day. Daily linear regression analyses of $\mathrm{Abs}_{\mathrm{ppt}}$ responses were evaluated using Microsoft Excel ${ }^{\circledR}$. If the coefficient of determination $\left(\mathrm{R}^{2}\right)$ was less than 0.990 , the process was repeated. The tannin content of plant extracts was determined from the slope and intercept values generated from the calibration curve and converted to a mass basis according to the mass of sample extracted.

\section{Method Evaluation}

Important aspects of the methodology were investigated to validate its use for analysis of plant tissues. Replicate samples of tamarisk foliage $(1 \mathrm{~g})$ were extracted with solvents prepared with DMF, dimethyl sulfoxide (DMSO), or ethanol (1:1 with water) and subjected to analysis as described above. Volumes of extract $(2,3$, and $4 \mathrm{~mL})$ and $0.04 \%$ methyl cellulose solution $(2,3$, and $4 \mathrm{~mL})$ were also evaluated in multiple combinations to determine the volume of $0.04 \%$ methyl cellulose needed to yield complete precipitation and reproducible results. The need for filtration of precipitate solutions was also evaluated.

\section{Tannin Variation in Tamarisk}

Three tamarisk samples were analyzed repeatedly to demonstrate method reproducibility. The tannin concentrations were determined each day and the grand mean and relative standard deviation (RSD) were calculated for each sample. Each of the remaining tamarisk foliage samples was 


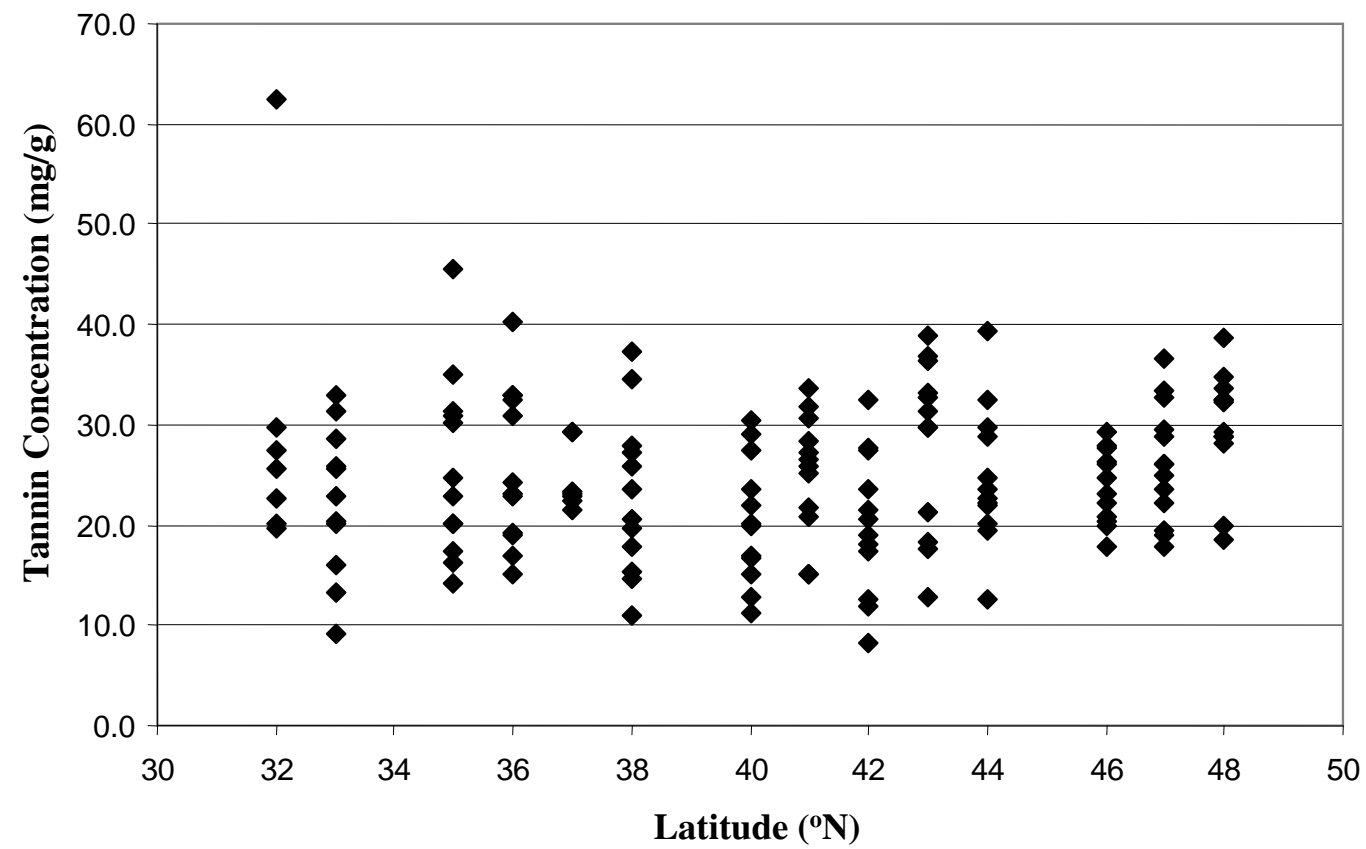

Fig. (1). Foliar tannin concentration (tannic acid equivalents) of tamarisk plants plotted with latitude of original plant collection location ( $\mathrm{r}=$ $0.07 ; p=0.38)$.

subjected to a single analysis. Tannic acid equivalents (t.e.q.) values were regressed against the latitude of plant origin (ranging from $32^{\circ}$ to $48^{\circ}$ North). Pearson correlation coefficients (r) were determined using the CORR procedure in SAS.

\section{RESULTS AND DISCUSSION}

The current method represents a simple tool for determining tannin concentrations in plant foliage samples with minimal sample preparation. DMF was selected for use in the extraction solvent after several organic modifiers were evaluated. Repeated extractions demonstrated that DMF produced greater extraction yield $(>20 \%)$ as compared to ethanol and better reproducibility (RSD $=1.6 \%)$ as compared to DMSO (5.9\%). Ascorbic acid, used in the extraction solvent to minimize tannin oxidation, was chosen for its minimal absorbance at $280 \mathrm{~nm}$. Evaluation of the methyl cellulose precipitation parameters indicated that using 3.0 $\mathrm{mL}$ of extract and $4 \mathrm{~mL}$ of $0.04 \%$ methyl cellulose solution resulted in complete precipitation. However, greater precision was noted with smaller volumes. Thus the optimal ratio of extract:methyl cellulose was preserved by using $0.75 \mathrm{~mL}$ extract and $1.0 \mathrm{~mL} 0.04 \%$ methyl cellulose solution. Filtration of treatment solutions following precipitation significantly reduced light scattering during spectroscopic analysis and resulted in a rugged and repeatable method.

Method reproducibility was good for repeated analysis of tamarisk samples, even when the analyses were repeatedly conducted on multiple days. The RSD obtained from analysis of three unique samples over several analysis days ranged from 3.9 to $7.9 \%$ and demonstrated the excellent repeatability of this method. Adaptation of the enological method represents a simple tool for determining tannin concentrations in plant foliage samples. We found sample size to have a sig- nificant impact on reproducibility - likely a result of our desire to analyze wet plant material. Improved precision among replicate analyses was obtained when at least two grams of homogenized plant material was extracted.

Tannin concentrations of tamarisk ranged from 8.26 to $62.36 \mathrm{mg} / \mathrm{g}$ t.e.q. (mean $24.86 \mathrm{mg} / \mathrm{g}$; RSD = 31\%). No correlation with latitude of tamarisk origination was observed for tannin ( $\mathrm{r}=0.07 ; p=0.38$; Fig. 1). Inherited variation in tamarisk cold hardiness was evident in the common garden and some of this variation was correlated with latitude [11]. Plants from the north survive colder temperatures than plants from the south, and plants from the same latitude often differ in cold hardiness. In the present study we found no latitudinal phenotypic variation in tannin production in tamarisk. Thus, there is no evidence of a gradient in natural selection favoring higher tannin concentrations at one latitude versus another. Experiments on the beetle introduced to control tamarisk in North America (Diorhabda elongata) have demonstrated considerable variation among individual tamarisks in their quality as a food source for the beetles [12]. While these data suggest that tannin concentration may contribute to individual variation, tannins are likely not responsible for observed latitudinal effects.

\section{ACKNOWLEDGEMENTS}

Mention of specific products does not constitute endorsement by the Monell Chemical Senses Center or United States Department of Agriculture. This research was made possible in part by funding from the City of Phoenix (AZ) Tres Rios Demonstration Wetlands project. The authors wish to thank Doreen Griffin for assistance with tamarisk collection and Julia Figueroa for assisting with sample homogenization. Drs. Jerome Hurley and Jae Kwak provided useful reviews of early drafts of the manuscript. 


\section{REFERENCES}

[1] Feeny P. Wallace JW, Nansel RL, Eds. Biological Interactions Between Plants and Insects. New York: Plenum Press Plant Apparency and Chemical Defense 1976; vol. 1, pp. 1-40.

[2] Rhoades DF, Rosenthal GA, Janzen DH, Eds. Herbivores. Their Interaction with Secondary Plant Metabolites. New York: Academic Press Evolution of Plant Chemical Defense against Herbivores 1979; vol. 1 pp. 3-54.

[3] Hagerman AE, Robbins CT. Specificity of Tannin-binding salivary proteins relative to diet selection by mammals. Can J Zool 1993; 71(3): 628-33.

[4] Kimball BA, Perry KR. Manipulating beaver (Castor canadensis) feeding responses to invasive tamarisk (Tamarix spp.). J Chem Ecol 2008; 34(8): 1050-6.

[5] Kennedy TA, Hobbie SE. Saltcedar (Tamarix ramosissima) invasion alters organic matter dynamics in a desert stream. Freshw Biol 2004; 49(1): 65-76.

[6] Going BM, Dudley TL. Invasive riparian plant litter alters aquatic insect growth. Biol Invasions 2008; 10(7): 1041-51.
Friedman JM, Auble GT, Shafroth PB, et al. Dominance of nonnative riparian trees in western USA. Biol Invasions 2005; 7(4): 747-51.

[8] Moline AB, Poff NL. Growth of an invertebrate shredder on native (Populus) and non-native (Tamarix elaeagnus) leaf litter. Freshw Biol 2008; 53(5): 1012-20.

[9] Montedoro G, Fantozzi P. Dosage des tannins dans les moûts et les vins á l'aide de la methyl cellulose et evolution d'autres fractions phenoliques. Lebensm Wiss Technol 1974; 7(3): 155-61.

[10] Sarneckis CJ, Dambergs RG, Jones P, Mercurio M, Herderich MJ, Smith PA. Quantification of condensed tannins by precipitation with methyl cellulose: development and validation of an optimised tool for grape and wine analysis. Australian J Grape Wine Res 2006; 12(1): 39-49.

[11] Friedman JM, Roelle JE, Gaskin JF, Pepper AE, Manhart JR. Latitudinal variation in cold hardiness in introduced Tamarix and native Populus. Evol Appl 2008; 1(4): 598-607.

[12] DeLoach CJ, Lewis PA, Herr JC, Carruthers RI, Tracy JL, Johnson J. Host specificity of the leaf beetle, Diorhabda elongata deserticola (Coleoptera : Chrysomelidae) from Asia, a biological control agent for saltcedars (Tainarix : Tamaricaceae) in the Western United States. Biol Control 2003; 27(2): 117-47.

(C) Hussey et al.: Licensee Bentham Open.

This is an open access article licensed under the terms of the Creative Commons Attribution Non-Commercial License (http://creativecommons.org/licenses/ by-nc/3.0/) which permits unrestricted, non-commercial use, distribution and reproduction in any medium, provided the work is properly cited. 